\title{
FORMAÇÃO INICIAL DO PROFESSOR PESQUISADOR ATRAVÉS DO PROGRAMA PIBIC/CNPQ: O QUE NOS DIZ A PRÁTICA PROFISSIONAL DE EGRESSOS?
}

\author{
Regina Celi Machado Pires*
}

Recebido em: 01 de dezembro de 2008

Aprovado em: 22 de março de 2009

\begin{abstract}
*Prof ${ }^{a}$ adjunto, Depto de Ciências Humanas, Universidade do Estado da Bahia, Campus I. Dra. em Educação, pela Universidade Federal do Rio Grande do Sul, linha de pesquisa - Universidade: teoria e prática. Foi bolsista do programa PQI/CAPES-UNEB. E-mail: tcheli@br.inter.net
\end{abstract}

Resumo: Este artigo versa sobre os resultados de uma pesquisa de doutorado (2008). O objetivo foi conhecer, analisar e explicar as contradições, harmonias, correspondências e diferenças existentes entre a formação inicial do professor pesquisador universitário, realizada pelo PIBIC/CNPq/UNEB e a prática profissional de seus egressos. A hipótese principal de trabalho entende que o egresso do PIBIC/CNPq se torna um professor pesquisador universitário. Acompanhamos o surgimento e desenvolvimento de órgãos que apoiaram a formação de recursos humanos para a pesquisa no país e ressaltamos o surgimento do CNPq (1951), com a criação da Bolsa do Estudante que viria a se tornar o PIBIC (1989). Trabalhamos com questionário eletrônico, entrevista semi-estruturada e análise de documentos. Detalhadamente, analisamos as Resoluções Normativas do PIBIC/CNPq e pesquisamos 87 egressos (69\%), em uma população de 127 (PIBIC/UNEB -1997-2007), com recorte para uma subamostra de 21 casos, que afirmaram estar na docência do ensino superior. Oito desses egressos foram entrevistados, em profundidade e suas falas categorizadas e analisadas, na perspectiva do materialismo histórico-dialético. Concluímos que, embora os egressos PIBIC/UNEB alcancem o mestrado na medida julgada satisfatória pelo CNPq, um professor da educação superior, nas condições de trabalho demonstradas, não consegue desenvolver pesquisa em nível de qualidade. As proposições visam um salto qualitativo indispensável à formação de novas gerações de professores pesquisadores. Essa preparação deve contemplar formação geral, filosófica e metodológica, orientada para a transformação do modo de produzir ciência, no país, partindo-se da concepção do pesquisador em bases reais, como um trabalhador e não como um ser idealizado e talentoso.

Palavras-chave: Formação professor-pesquisador. Universidade. Iniciação científica. PIBIC/CNPq. Avaliação de egressos.

\section{UNDERGRADUATE STUDIES OF THE RESEARCH PROFESSOR THROUGH THE PIBIC/ CNPQ PROGRAM: WHAT DOES THE PROFESSIONAL PRACTICE OF GRADUATES TELL US?}

\footnotetext{
Abstract: This article discusses the results of a Ph.D. research (2008). The purpose of this research was to understand, analyze and explain the contradictions, harmonies, similarities and differences between the undergraduate studies of university research professors, held by PIBIC/CNPq/UNEB, and the professional practice of its graduates. The main work hypothesis was that the graduates of PIBIC/CNPq of UNEB would become university professors and researchers. The work follows the emergence and development of agencies that support the development of human resources for research in Brazil and highlights the emergence of CNPq (1951), with the creation of the Student Scholarship that would later become PIBIC (1989). Electronic questionnaire, semi-structured interview and document analysis were used. The Normative Resolutions of PIBIC/CNPq were analyzed in detail, and 87 (69\%) in a population of 127 graduates (PIBIC/UNEB -1997-2007) were researched, with a subsample of 21 cases, who stated to be teaching in higher education. Eight of these graduates were interviewed in depth, and their speeches were categorized and analyzed, through the perspective of historical and dialectical materialism. The conclusion was
} 
that, although the graduates of PIBIC/UNEB reach the Master's Degree to a level considered satisfactory by CNPq, a higher education professor, under the demonstrated working conditions, is not able to develop good quality research. The propositions presented aim at a qualitative leap which is essential to the education of new generations of research professors. This preparation must include a general, philosophical and methodological education, focused on transforming the way of producing science in Brazil, starting from a concept that regards the actuality of the researcher, that is, as a worker, and not as an idealized and talented being.

Keywords: Researcher-professor education. University. Scientific introduction. PIBIC/CNPq. Evaluation of graduates..

\section{Introdução}

Como anuncia o título da tese (PIRES, 2008), o estudo que trata esse artigo se desenvolve considerando a contradição entre um fenômeno material social (FMS) que chamamos de "formação inicial do professor pesquisador universitário no programa PIBIC/CNPq" e outro que é a "prática profissional de seus egressos". O primeiro fenômeno trata da "formação" e nos leva ao mundo das idéias, da teoria; o segundo nos transporta para o mundo da realidade objetiva e nos conduz a pensar em trabalho.

O propósito de dar continuidade, "estranhar", descobrir de novo, a investigação realizada durante o curso de mestrado na Universidade Federal da Bahia (UFBA, 2002) justificou a realização da pesquisa. Naquela ocasião, o interesse em pesquisar sobre iniciação científica (IC) decorreu da nossa prática, como Gerente de Pesquisa da Universidade do Estado da Bahia - UNEB, período em que tivemos a oportunidade de implantarmos os primeiros Programas de Bolsa de Iniciação Científica (BIC), nessa Universidade.

Trata-se, portanto, de um estudo de caso de natureza qualitativa e quantitativa, sob a abordagem do materialismo histórico-dialético que caracteriza um modo particular de pensar e de fazer ciência: o marxismo. Adotamos uma compreensão de mundo que pensa as suas coisas de maneira diferente da lógica formal e linear, na qual a maior parte das pessoas, como nós, foram formadas. Estamos nos propondo a pensar de forma dialética, para encontrar o sentido dos fenômenos, apreendendo o movimento de seus processos de desenvolvimento, isto é, buscando encontrar as suas contradições.

Apoiamo-nos no marxismo clássico de Marx (2002, 1983), Marx e Engles (1984), Gramsci (2004) e no marxismo contemporâneo de Mészáros (2005, 2004), Wood (2003), Eagleton (1999), Kosik (2002), Antunes (2006), Oliveira (2003), Chauí (1999), Triviños (2006; 1987) e muitos outros que vêm realizando as mudanças teóricas necessárias às novas compreensões históricas dos fenômenos materiais sociais, sustentadas no materialismo histórico. No estudo do 
materialismo dialético, baseamo-nos, sobretudo, em Cheptulin (1982) e Pinto (1979). Em Leite (2005; 1990), Dias Sobrinho (2005; 2002), Santos (2004; 2003), Búrigo (2007), Silva Júnior (2007), Franco, Fialho e Pires (2006), para ressaltar alguns, buscamos as referências sobre a educação superior, especialmente, sobre a universidade brasileira e mundial.

\section{Hipótese de trabalho e objetivos da pesquisa}

Quando nos detivemos no estudo da produção do conhecimento sobre políticas de Ciência e Tecnologia (C\&T) no Brasil, constatamos que os estudiosos não o consideram ainda suficientemente desenvolvido (ALBUQUERQUE et al., 2002; ALMEIDA, 2002). Ao restringir a questão à IC, evidenciamos que essa produção praticamente não existe e, com relação aos estudos sobre a universidade, na perspectiva do materialismo histórico-dialético, apreendemos que ainda há uma grande carência.

Observamos que as condições históricas de desenvolvimento da pesquisa científica no Brasil, de forma mais sistemática, ligam-se aos programas de pósgraduação das universidades e às suas fontes de fomento. Então, raciocinamos que o desenvolvimento do PIBIC/CNPq, como espaço de formação inicial do pesquisador, deve estar correlacionado com o processo de mudanças que vem ocorrendo, na educação superior brasileira, desde a criação do Sistema de Pós-Graduação. Esse, por sua vez, está articulado a um processo mais geral, internacional, desse nível de educação.

Visto que o PIBIC/CNPq objetiva inserir o ex-bolsista, em um mestrado e doutorado, ou seja, em um programa de stricto sensu, estabelecemos como a hipótese principal de trabalho, a idéia de que o egresso do PIBIC/CNPq UNEB se torna um professor pesquisador universitário. Ao nos perguntarmos: para onde irão, depois de formados, os futuros mestres e doutores, oriundos do programa de PIBIC? Imaginamos que a resposta seria: para a universidade.

Tal hipótese ganhou especial reforço quando analisamos os propósitos do PIBIC, através de sua legislação específica, que são as Resoluções Normativas $(\mathrm{RN})$ : o objetivo que se mantém é aquele relacionado ao "preparar clientela qualificada para os programas de pós-graduação", como reza a primeira $(\mathrm{CNPq}$. RN-005/1993); e, também, o objetivo de "contribuir de forma decisiva para reduzir o tempo médio de titulação de mestres e doutores", como está em todas as RN, inclusive na vigente (CNPq. RN-017/2006)

Guiando-nos por essa hipótese, estabelecemos o objetivo geral do estudo: conhecer, analisar e explicar as contradições, harmonias, correspondências e 
diferenças existentes entre a formação inicial do pesquisador, realizada pelo Programa PIBIC/CNPq da UNEB e a prática profissional dos egressos desse mesmo Programa.

Para a realização da pesquisa de tese, firmamos os seguintes objetivos específicos:

a) identificar e localizar os egressos dos PIBIC/CNPq-UNEB, do período 1997-2007;

b) descrever a prática profissional desses egressos, explicando as causas que condicionam a continuidade da formação do professor pesquisador universitário;

c) avaliar o processo da formação daqueles alunos que receberam o apoio de uma bolsa auxílio do PIBIC/CNPq, na Universidade do Estado da Bahia, a partir da prática profissional do ex-bolsista que está atuando na docência do ensino superior;

d) propor medidas e sugestões que venham a contribuir para a superação das contradições identificadas e para uma política de formação do professor/pesquisador que lhe permita as condições materiais e espirituais necessárias à continuidade da sua formação, assim como para a mudança e transformação da sua vida e da realidade que o rodeia.

\section{Delimitação do objeto de estudo}

Nossos estudos sobre os programas de Bolsa de IC (BIC), o demarcou como um espaço da formação inicial do professor pesquisador universitário, desde a graduação, que caracteriza "modos" de produzir o conhecimento científico, na Universidade. Compreendemos essas relações como a fonte do desenvolvimento do processo de vir a ser um professor pesquisador universitário e distinguimos as características/propriedades dessa formação material, como sendo, por exemplo: Projeto de pesquisa do orientador; Plano de trabalho do bolsista; Aluno/bolsista; Professor/orientador; Programa PIBIC/CNPq; Programa PICIN/UNEB; Programa IC/FAPESB; Grade curricular do curso de graduação; Laboratórios; Salas de aula; Biblioteca; Fomentos à pesquisa e à Pós-Graduação (CNPq; CAPES; FAPESB; recursos da própria universidade; empresas; outros); Carga horária do bolsista (20 horas) e do orientador (DE); Legislações: federais; estaduais e institucionais (editais); Leis trabalhistas 
(municipal, estadual, federal); Contrato de trabalho; Salário (remuneração); Sindicato; Sistema de avaliação institucional: CNPq, CAPES, Universidade e os documentos que servem à avaliação das BIC (relatório de pesquisa do orientador; relatórios parciais e anuais do bolsista; Jornadas de IC da UNEB; livros de resumos).

Qual dessas propriedades é o prioritário?

Entendemos por prioritário, o aspecto ou propriedade de um fenômeno material social que exprime a relação fundamental e determinante (CHEPTULIN, 1982). Logo, identificamos os Programas de Iniciação Científica como o aspecto que exprime a relação fundamental e determinante da correlação dialética existente na unidade: estudante/bolsista e pesquisador/orientador. O Programa de BIC, através de suas legislações específicas, define todos aqueles aspectos, anteriormente mencionados, os quais configuram a forma de organização do trabalho acadêmico-científico nas universidades e a formação daqueles que o produzem (CALAZANS, 1987, 2002). Para realizarem tal prática, esses atores da pesquisa científica, necessariamente, entram em relação cotidiana com outros profissionais e/ou instituições, na universidade, como os funcionários técnico-administrativos, as Fundações, os prestadores de serviços, a comunidade, entre outros.

Auxiliadas por essa ferramenta do prioritário - o Programa de BIC, partindo do momento presente e iniciando a investigação pelo particular que é formação inicial do professor pesquisador universitário do Programa PIBIC/UNEB, conseguimos visualizar a totalidade do processo da formação dos egressos desse Programa, isto é, daqueles que estão, hoje, na prática da docência, como professor do ensino superior e que, desse lugar, refletem sobre a sua prática, ao tempo em que avaliam a sua formação de pesquisador, iniciada no PIBIC/UNEB.

O tempo de duração da formação material, em estudo, estende-se de 1997 (ano da primeira turma de egressos PIBIC/UNEB) a 2007 (ano da última turma de egressos desse Programa). Tal período não resulta simplesmente de uma escolha arbitrária do pesquisador, mas refere-se aos ritmos históricos a que está submetido o processo de desenvolvimento do fenômeno estudado. A categoria "movimento" do materialismo dialético é a categoria "história", no materialismo histórico, indicando que no "tempo histórico", tempo e movimento determinam-se, reciprocamente, diz Triviños (1987).

A partir dessa delimitação, fizemos a seguinte indagação de pesquisa: $\mathrm{O}$ processo de iniciação científica, que se realiza no PIBIC/CNPq, da Universidade do Estado da Bahia, no período 1997 a 2007, está formando professores pesquisadores? 


\section{Universidade, ciência \& tecnologia}

Buscamos entender o movimento histórico do nosso objeto de estudo, em suas relações com o desenvolvimento de uma política de C\&T e a forma com que esse processo buscou a incorporação da Inovação, como meio de alavancar o desenvolvimento econômico, no país.

Situamos essa análise no tempo atual da educação superior brasileira, compreendendo essa contemporaneidade como o produto histórico de um processo, que está submetido a um ritmo, cujo tempo é sinalizado por contradições ocorridas no seu interior, gerando mudanças profundas nesse nível de ensino. Essas contradições resultam de condições econômicas sociais - da luta de classes interna no país - que geram certas correlações de forças, que se materializam em acordos políticos, isto é, em legislações (marcos legais) que vão moldando as características da universidade, quando lhe designam determinado papel que, depois, se contrapõe a outra finalidade maior. Por exemplo: colocando a pós-graduação universitária como o principal locus da pesquisa científica, ou seja, no setor "não produtivo" e depois se perguntando: como inserir essa riqueza técnico-científica no desenvolvimento econômico, isto é, no setor "produtivo"? Enfim, uma contradição que se dá no marco da contraposição público-privado, embora, ideologicamente, a ênfase da discussão se desvie para o estatal/mercantil.

Um primeiro marco contraditório que apontamos foi a Lei ${ }^{0} 5.540 / 68$ (BRASIL, 2002), a conhecida Reforma Universitária de 1968; a Constituição Federal de 1988 (BRASIL, 2003) foi o segundo grande marco; e o Plano Diretor da Reforma do Aparelho do Estado (BRASIL, 1995), juntamente com a Lei 9394/96 (BRASIL, 1996), o terceiro marco. A concepção de universidade, nessas legislações, diz que os cursos de graduação seriam concebidos no tripé do ensino, pesquisa e extensão. Porém, tal concepção para a graduação é uma possibilidade formal, na medida em que o que realmente acontece é o ensino de formação da mão-de-obra para o mercado de trabalho. Pesquisa, de fato, na graduação, fez-se por meio desses programas de BIC, porque oferecem alguma condição material aos alunos/bolsistas que, orientados por professores/ pesquisadores, conseguem realizar pesquisa.

\section{$\mathrm{O} \mathrm{PIBIC/CNPq}$}

Em nossos estudos, localizamos o surgimento de associações e órgãos no Brasil que apoiaram a formação de recursos humanos para a pesquisa, como elementos de P\&D. Dentre esses, detivemo-nos no momento de criação do CNPq (1951), com o evento de criação da Bolsa do Estudante. (MARCUSCHI, 1996) 
Embora criadas desde a década de 50, as BIC se desenvolvem, timidamente, por algumas décadas, até alcançarem um número significativo, em fins dos anos 80, quando dão um "salto" quantitativo, acontecendo a criação do Programa Institucional de Bolsas de Iniciação Científica - PIBIC (1989). O PIBIC vai inaugurar no CNPq, uma nova modalidade de concessão de bolsa BIC às IES, pelo sistema de quotas institucionais, mas essa Agência mantém as quotas concedidas, tradicionalmente, ao coordenador do projeto integrado de pesquisa, que continuam vigorando. Regulado por Resoluções Normativas, da primeira RN à ultima vigente, totalizam-se nove. No período em estudo, aconteceram duas avaliações nacionais do PIBIC: em 1996, coordenada pelo professor Marcuschi; em 1999, sob a coordenação do professor Aragón.

A trajetória do número de quotas do PIBIC, no período 1996/2008¹, pode ser visualizada no Quadro 1, que construímos a partir de dados fornecidos pela Coordenação Nacional do PIBIC/CNPq, e por consulta ao sítio do CNPq:

\begin{tabular}{|c|c|c|c|c|c|c|c|c|c|c|c|c|}
\hline Período & $\begin{array}{r}1996 / \\
1997\end{array}$ & $\begin{array}{r}1997 / \\
1998\end{array}$ & $\begin{array}{r}1998 / \\
1999\end{array}$ & $\begin{array}{r}1999 / \\
2000\end{array}$ & $\begin{array}{r}2000 / \\
2001\end{array}$ & $\begin{array}{r}2001 / \\
2002\end{array}$ & $\begin{array}{r}2002 / \\
2003\end{array}$ & $\begin{array}{r}2003 / \\
2004\end{array}$ & $\begin{array}{r}2004 / \\
2005\end{array}$ & $\begin{array}{r}2005 / \\
2006\end{array}$ & $\begin{array}{r}2006 / \\
2007\end{array}$ & $\begin{array}{l}2007 / \\
2008^{*}\end{array}$ \\
\hline Quotas & 13.771 & 14.175 & 14.187 & 14.191 & 14.435 & 14.500 & 12.984 & 14.431 & 14.909 & 14.230 & 17.064 & 18.782 \\
\hline
\end{tabular}

Quadro 1 - Evolução da Quantidade de Quotas do PIBIC/CNPq, 1996/2008

Fonte: Coordenação do PIBIC/CNPq. Brasília/DF, Julho, 2005; Outubro, $2007^{2}$.

Em 2003, o CNPq criou outra modalidade de bolsas institucionais, o Programa de Bolsa de Iniciação Científica Júnior (PIBIC Junior, 2006) para o ensino médio, cujas quotas de BIC são repassadas às Fundações de Amparo à Pesquisa (FAP). Sucedendo-se a essa experiência, em 2007, foi criado o Programa Institucional de Bolsas de Iniciação em Desenvolvimento Tecnológico e Inovação - PIBITI (2008).

A UNEB, unidade em análise da pesquisa, é uma universidade multicampi, pública, mantida pelo Governo do Estado da Bahia, através da Secretaria de Educação. Encontra-se presente, geograficamente, em todas as regiões desse Estado, através dos seus 29 Departamentos, com sede em Salvador e 24 campi, instalados em centros regionais de médio e grande porte.

1 Apesar do "impulso" do PIBIC, conforme se refere Marcuschi (1996), no inicio dos anos 90, a quantidade de quotas destinadas às IES permaneceu praticamente a mesma, no período 1996-2005. O valor da bolsa aluno, após ter sido reajustado, em maio de 1996, para R \$241,51 ficou "congelado" durante uma década, somente sendo reajustado para $\mathrm{R} \$ 300,00$, em agosto de 2005, valor não alterado, desde então (abr. 2008).

2 CNPq. PIBIC - Quota 2007/2008. Disponível em: < http://www.cnpq.br/programasespeciais/pibic/ quota07-08.htm>. Acesso em: 19 dez. 2007. 
O PIBIC/CNPq é implantado na UNEB, em 1996. Para atender à contrapartida financeira exigida pela RN daquele momento (CNPq. RN-006/1996), foi criado o atual Programa de IC da UNEB - PICIN. Em 2003, entra em cena um novo agente financiador: a Fundação de Apoio à Pesquisa do Estado da Bahia - FAPESB, que, disponibilizando, inicialmente, 35 Bolsas de Iniciação Científica (BIC), alcança 2007 com 100 bolsas (Quadro 2). Na UNEB, essas BIC têm valores diferentes, segundo o tipo de Programa, embora suas sistemáticas de funcionamento sejam semelhantes.

Quando falamos do egresso do PIBIC/CNPq-UNEB, hoje professor do ensino superior, imediatamente dois momentos da formação desse egresso aparecem: o momento da sua formação inicial para a pesquisa, enquanto exaluno de um curso de graduação da UNEB que recebia um auxílio financeiro do PIBIC/CNPq; e outro que é o momento presente da vida desse egresso, como um professor/pesquisador universitário. Em nosso entendimento, esse segundo momento é a "validação" da formação inicial do ex-aluno/bolsista do PIBIC/UNEB. Pela lógica dialética, entendemos que o momento presente, isto é, a prática do egresso PIBIC/UNEB traz anulado o momento anterior da sua formação graduada e é essa "prática social" que será o nosso critério de verdade científico.

A distribuição das BIC na UNEB, por Programa, desde o ano de sua implantação (1996) até o período do seu último edital de convocação (2007), se faz segundo o Quadro 2:

\begin{tabular}{|r|c|c|c|c|}
\hline \multirow{2}{*}{ ANO } & \multicolumn{2}{|c|}{ PROGRAMA } & \multirow{2}{*}{ TOTAL } \\
\cline { 2 - 4 } & PIBIC & PICIN & FAPESB & \\
\hline 1996 & 20 & - & - & 20 \\
\hline 1997 & 20 & 13 & - & 33 \\
\hline 1998 & 20 & 32 & - & 52 \\
\hline 1999 & 20 & 35 & - & 55 \\
\hline 2000 & 20 & 39 & - & 59 \\
\hline 2001 & 20 & 60 & - & 80 \\
\hline 2002 & 19 & 59 & - & 79 \\
\hline 2003 & 19 & 40 & 35 & 94 \\
\hline 2004 & 19 & 80 & 40 & 139 \\
\hline 2005 & 24 & 60 & 70 & 154 \\
\hline 2006 & 34 & 60 & 100 & 194 \\
\hline 2007 & 34 & 42 & 100 & 176 \\
\hline
\end{tabular}

Quadro 2 - Quotas de BIC atendidas por Ano/Programa na UNEB (1996-2007)

Fonte: Gerência de Pesquisa/PPG/UNEB, jan. 2008.

Nota: Valores das bolsas informados pela Gerência de Pesquisa/PPG/UNEB: PIBIC (R\$300,00); PICIN (R\$260,00); FAPESB (R\$350,00). 


\section{Idéias como forças produtivas} e modos de consciência

O capital financeiro, forma contemporânea hegemônica do capital, torna o conhecimento e a informação forças vitais à intensificação de sua reprodução e acumulação (CHAUÍ, 1999; DIAS SOBRINHO, 2005). Diferentes valores de troca são atribuídos ao conhecimento, dada a sua capacidade de gerar valor mais rapidamente, agregando-lhe riqueza e potencial de competitividade elevado. Assim, aquele conhecimento relacionado com os processos de inovação tecnológica e produção industrial são os valiosos para a chamada "economia do conhecimento", a qual vem retomando e reforçando, nas últimas décadas, a teoria do capital humano, para a economia globalizada de nossos dias. Nela, o lugar do conhecimento, do saber, do pensamento, é o de força produtiva, enquanto o princípio ativo fundamental das empresas.

Se concebermos que, filosoficamente, o homem pode ser definido como "o ser que produz sua existência” (PINTO, 1979, p. 48) e que o conhecimento é uma propriedade geral da matéria viva, que acompanha o processo evolutivo desta, em um processo particular de desenvolvimento denominado “hominização", também conceberemos que a consciência é uma forma de reflexo da realidade que se apresenta na matéria mais altamente organizada - o cérebro humano. Essa forma organizada do cérebro foi alcançada através do trabalho humano e do desenvolvimento social e não somente é resultante de mudanças fisiológicas ocorridas no cérebro do homem (CHEPTULIN, 1982, p. 88). Com isso queremos assinalar que o conceito de "produção" torna-se essencial à compreensão da essência do homem e de todas as suas atividades, incluindo-se a mais perfeita dela, a ciência.

Existencialmente, a idéia é considerada um bem. Essa é a sua expressão geral e primordial de onde deriva, secundariamente, a sua significação econômica, fundamentada na produção social do trabalho e incorporada à economia da sociedade. Nessa perspectiva, aparece a essência contraditória da idéia: enquanto resultado do trabalho humano é um bem de consumo; e enquanto fonte geradora da atuação do homem para a criação de novos processos de produção de objetos e fenômenos, a idéia é um bem de produção. "Em virtude deste segundo aspecto, as idéias têm de ser contadas entre as forças sociais de produção". (PINTO, 1979, p. 48). Estamos, portanto, considerando a idéia, no seu curso da operação sobre o mundo, onde elas atuam como forças produtivas reais.

A compreensão da natureza dialética da idéia, como um bem de produção e como um bem de consumo, torna-se um problema do qual resulta a questão 
da alienação da consciência do pesquisador, uma vez que "a consciência se constitui pela interação do pensamento e da prática no ato do trabalho produtivo" (PINTO, 1979, p. 55), de onde emergem "modos de consciência” do pesquisador, a consciência crítica ou ingênua (alienada).

\section{Abordagem teórico-metodológica}

Por estudos que realizamos sobre o desenvolvimento do método materialistadialético nas obras de Marx (TRIVIÑOS, 2006a, 2005), reconhecemos que o "estudo de caso" já fora desenvolvido por esse autor, desde 1859, embora, ainda, não assim denominado. Hoje, o "estudo de caso" é uma das abordagens qualitativas de pesquisa mais utilizadas por nós, pesquisadores educacionais.

Portanto, enquanto investigação de natureza qualitativa, o desenvolvimento do estudo seguiu o "método marxiano", o qual concebe a pesquisa científica como um trabalho sistematizado em dois grandes momentos: o método de investigação e o método de exposição, em um movimento que se dá do "concreto sensível" ao "concreto lógico". As leis e categorias do materialismo dialético cumprem funções ideológica, gnoseológica e metodológica, que guiam a pesquisa empírica, segundo a prática de Marx e Engels (1984, p. 21):

O fato é, portanto, este: o de determinados indivíduos, que trabalham produtivamente de determinado modo, entrarem em determinadas relações sociais e políticas. A observação empírica tem de mostrar, em cada um dos casos, empiricamente e sem qualquer mistificação e especulação, a conexão da estrutura social e política com a produção. A estrutura social e o Estado decorrem constantemente do processo de vida de determinados indivíduos; mas destes indivíduos não como eles poderão parecer, na sua própria representação ou na de outros, mas como eles são realmente, ou seja, como agem, como produzem materialmente, como trabalham, portanto, em determinados limites, premissas e condições materiais que não dependem da sua vontade.

A pesquisa empírica foi realizada por questionário eletrônico, entrevista semi-estruturada e análise de documentos. Analisamos, detalhadamente, todas as Resoluções Normativas do PIBIC/CNPq. Já o trabalho de campo envolveu: levantamento inicial de todos os egressos dos programas PIBIC e PICIN da UNEB, junto aos arquivos da PPG/UNEB, para o período 1997-2006; decisão de trabalhar apenas com os egressos do PIBIC/UNEB e chegamos um número real $^{3}$ de 127 egressos do PIBIC/CNPq-UNEB que constitui a popula-

3 Nesse levantamento, chegamos a um total de 596 egressos, sendo 419 do PICIN e 197 do PIBIC. Com 
ção da pesquisa; concentração de nossos esforços nessa população e o início do que chamamos de "caça aos egressos", pelos diversos meios; elaboração e encaminhamento do questionário eletrônico, aos egressos localizados e a obtenção de 87 respostas (69\%, amostra casual), com a respectiva tabulação eletrônica dos dados, concomitantemente; identificação de 21 egressos, que estão na prática da docência no ensino superior (ES), constituindo-se a sub-amostra casual da pesquisa; seleção de oito desses egressos para entrevista semi-estruturada, a partir de critérios ${ }^{4}$, compondo-se a amostra intencional do estudo; elaboração do roteiro de entrevista, envolvendo perguntas "básicas" e "derivadas" (TRIVIÑOS, 1987), a partir da teoria que orienta o estudo; realização do "teste piloto".

A análise, interpretação, explicação e compreensão das informações das questões abertas do questionário e do conteúdo das entrevistas, foram feitas a partir das categorias do materialismo histórico-dialético e da economia política. Para as entrevistas semi-estruturadas, estabelecemos as seguintes categorias empíricas: vida pessoal e familiar; experiência profissional e relação teoria/prática; ingresso no mercado de trabalho; ambiente de trabalho, remuneração salarial e relação com colegas; atividades rotineiras, lazer e os meios de comunicação; formação atual e passada do professor pesquisador e os programas de bolsas para pesquisa; recomendações para aprimorar os programas de incentivo à pesquisa.

Utilizamos o método estatístico para a descrição analítica das informações que obtivemos das questões fechadas do questionário eletrônico, apropriandonos do SPSS 5 e nos inspirando em Pinto (1979), que trata das possibilidades e limites desse método, no pensamento lógico dialético.

\section{Resultados}

Ao identificar e localizar os egressos dos PIBIC/CNPq-UNEB do período 1997-2007, observamos que os quatro Departamentos do Campus I/Salvador concentram mais da metade (53,0\%) de todos os 127 egressos, enquanto o Campus III-Juazeiro detém cerca de 26,0\%.

Outro tipo de concentração dessa população acontece com relação à distribuição dos ex-bolsistas, por área do conhecimento dos projetos de pesquisa da IC, segundo mostra o Gráfico 1:

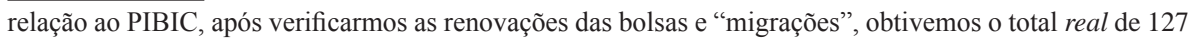
egressos.

4 Os critérios foram: egresso formado há 3 anos; trabalhando como professor do ES; dedicando-se ao ensino e realizando pesquisa, financiada ou não, pelo CNPq ou outra fonte de fomento.

5 Statistics Packet for Social Sciences (Pacote Estatístico para as Ciências Sociais). 


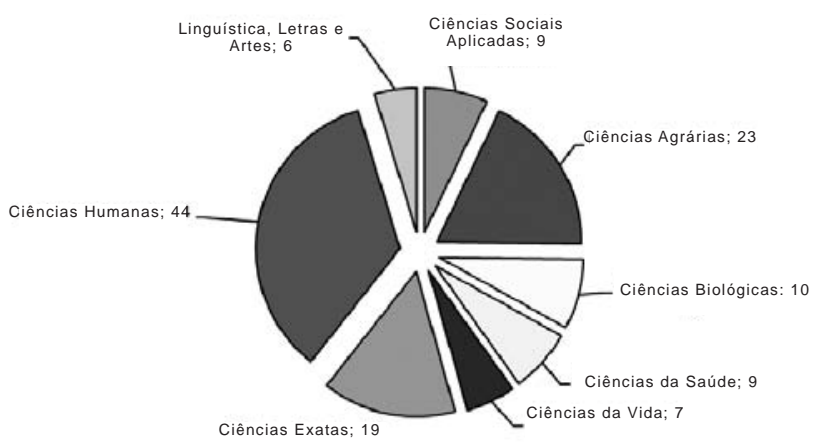

Gráfico 1 - Distribuição dos egressos PIBIC/CNPq - UNEB,

por área de conhecimento - 1997/2007

Fonte: Gerência de Pesquisa - PPG/UNEB, nov. 2006.

Sobre os resultados da amostragem casual ${ }^{6}$ : o egresso PIBIC/CNPq-UNEB (1997-2007) tem idade entre 25 a 34 anos (85\%), é do sexo feminino (57,5\%), foi um aluno diurno e o PIBIC foi seu primeiro programa de IC $(76,1 \%)$, tendo renovado a bolsa (85,9\%), uma vez (57,1\%). Esses egressos provêm das áreas das Ciências Humanas (44 casos), Ciências Agrárias (23) e Ciências Exatas e da Terra (19), sobressaindo-se os cursos da graduação de Pedagogia, Engenharia Agronômica e Licenciatura em Química Aplicada, respectivamente. Afirmam que pesquisam (49 casos) e 27 fizeram ou estão fazendo o mestrado, confirmando a proporcionalidade de casos achados por Aragón (1999, p. 37). Os cursos de mestrado se concentram nas áreas de Ciências Humanas, Ciências Exatas e da Terra e Ciências Agrárias, seguindo a lógica da concentração geral da população de egressos PIBIC/UNEB. Alcançaram o doutorado apenas 10 egressos (11,5\%), sendo que 6 receberam ou estão recebendo bolsa, concedidas pelo CNPq, CAPES e FAPEMIG. A área de Ciências Exatas e da Terra é a que está conseguindo melhores resultados, com relação ao ingresso de ex-bolsistas no mestrado (6 casos), na mesma área de conhecimento da graduação, assim como no doutorado (4 casos), todos egressos dos cursos de Licenciatura em Química Aplicada e de Engenharia Agronômica. Então, a Área que mais forma egressos graduados, não é a mesma que forma mais mestre e doutores. A maior parte dos egressos dessa amostra (41,2\%) está trabalhando no setor público, em

6 Devido à pequena população do estudo (127 egressos) e suas respectivas, amostra e subamostra, realizamos a análise descritiva para as questões do questionário, adotando um procedimento que consiste em expressar o número de casos, ora em percentuais, ora em números absolutos. 
uma instituição de grande porte (54,1\%), entretanto, o vínculo empregatício predominante é o da CLT (29,4\%), seguido do estatutário (21,2\%). Creditamos esse "fenômeno" aos egressos da Engenharia Agronômica, que trabalham em empresas públicas de direito privado, sob regime jurídico da CLT. Com relação ao salário, os egressos se mostram insatisfeitos (58,8\%).

Um dos objetivos do questionário foi identificar o tipo de trabalho atual do egresso PIBIC/UNEB (1997-2007). Obtivemos uma diversidade de ocupações, sendo que 38,0\% delas estão ligadas à docência, em seus três níveis: Ensino Fundamental, Ensino Médio e Ensino Superior, conforme se pode observar no Gráfico 2:

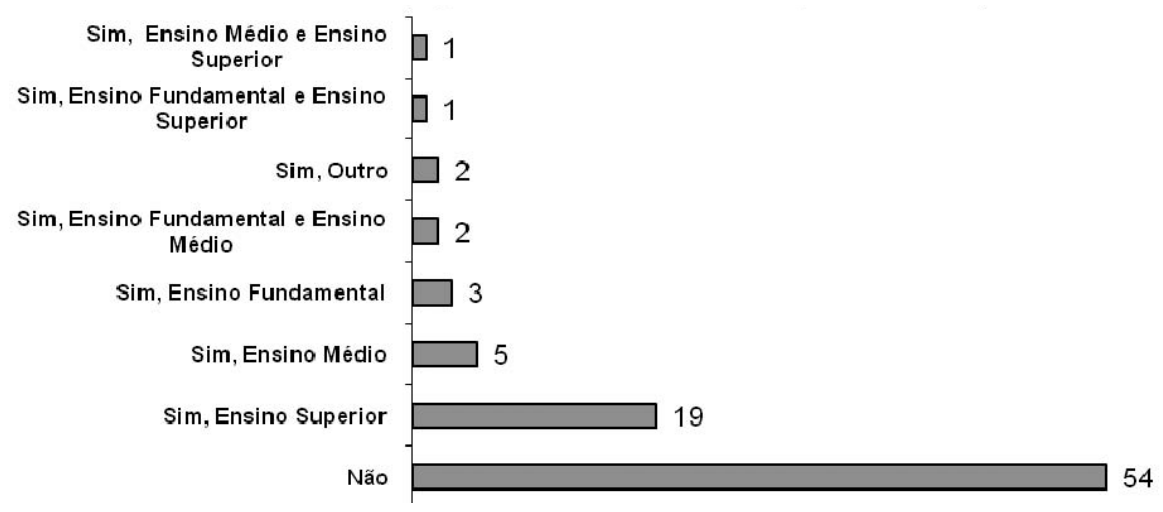

Gráfico 2 - Exerce atividade docente? (egressos PIBIC/UNEB, 1997-2007)

Fonte: Coleta por questionário eletrônico fev./out. 2007.

A nossa hipótese de trabalho exigiu que colocássemos a lente sobre os 21 egressos PIBIC/UNEB (1997-2007) que estão na docência da Educação Superior (Gráfico 2).

Uma caracterização geral dessa subamostra casual, diz que esse egresso professor da ES tem idade entre 25 e 34 anos, é do sexo feminino, está trabalhando em Instituições de Ensino Superior (IES) localizadas na cidade de Salvador/ BA e pertence às primeiras turmas do PIBIC-UNEB (1997, 1998, 1999). A área das Ciências Humanas ( 8 casos) é a que mais tem contribuído para a profissão de professor universitário, através do curso de Pedagogia (5).

"Você pesquisa?" 19 professores universitários egressos do PIBIC/UNEB responderam "Sim" (90,48\%); entretanto, apenas 4 desse professores $(19,05 \%)$ afirmaram que recebem algum tipo de fomento para pesquisar, conforme ilustram os Gráficos 3 e 4, respectivamente: 


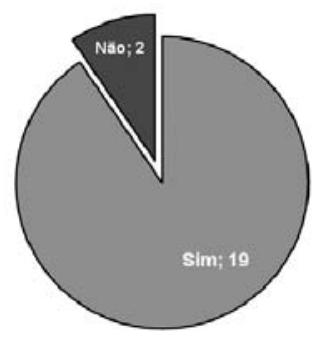

Gráfico 3 - Você pesquisa? (egressos PIBIC/UNEB docentes ES)

Fonte: Coleta por questionário eletrônico fev./out. 2007.

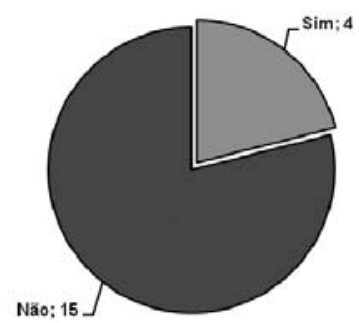

Gráfico 4 - Recebe algum tipo de fomento para pesquisar:

(egressos PIBIC/UNEB docentes ES)

Fonte: Coleta por questionário eletrônico fev./out. 2007.

Estão fazendo ou já fizeram o mestrado 16 egresso (Gráfico 5), porém, apenas 6 egressos docentes obtiveram bolsa, enquanto cursaram o mestrado, provindas da CAPES, CNPq, FAPESB, UNEB e UESB (Universidade do Sudoeste da Bahia):

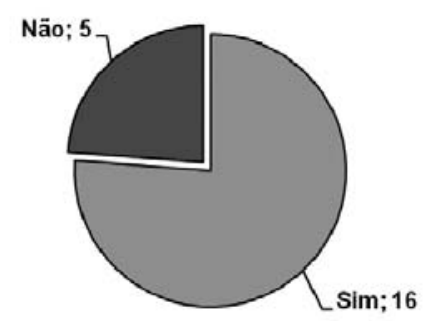

Gráfico 5 - Fez ou está fazendo mestrado?

(egressos PIBIC/UNEB docentes ES)

Fonte: Coleta por questionário eletrônico fev./out. 2007. 
Ao curso de doutorado chegaram 7 egressos docentes ES (Gráfico 6), sendo 3 com fomento (2 CNPq; 1 CAPES), dos quais 2 foram contemplados com bolsa de mestrado e doutorado.

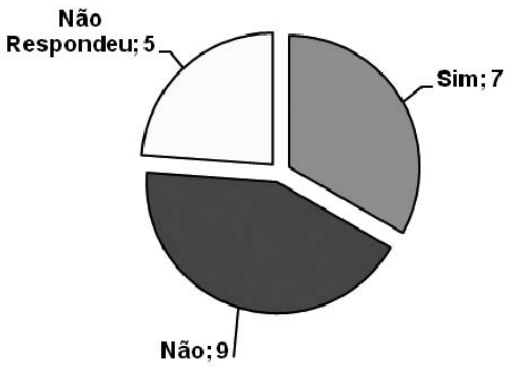

Gráfico 6 - Fez ou está fazendo doutorado?

(egressos PIBIC/UNEB docentes ES)

Fonte: Coleta por questionário eletrônico fev./out. 2007.

A área predominante do curso de mestrado e doutorado é a de Ciências Exatas e da Terra. Com esse resultado percebe-se que, no momento de um maior afunilamento dos recursos, a área de Ciências Humanas não se sobressai. Essa área, juntamente com as ciências sociais aplicadas, mostrou a ocorrência de uma maior "migração" de seus egressos, originários da BIC, para outras áreas do mestrado e do doutorado, e isso não é bem visto pelo CNPq, segundo deduzimos de estudo de Aragón (1999). A instituição pública, de grande porte, é onde a maior parte (10 casos) dos egressos exerce a docência, sendo que três, concomitantemente, estão em IES privadas, o que se reflete no tipo de vínculo empregatício híbrido do tipo "CLT e Estatutário". Praticamente todos confirmam que pesquisam (19 casos), entretanto, 4 afirmaram que recebem algum tipo de fomento para pesquisar, advindos da FAPESB, CNPq e do Ministério da Saúde. Para 16 desses egressos, o PIBIC foi a primeira BIC e 17 renovaram a bolsa, a maioria, uma vez.

Existe uma diferença entre o nível de insatisfação, com relação ao salário, da amostra casual e da subamostra do PIBIC/UNEB. O egresso professor do ES expressa maior insatisfação $(71,4 \%)$. Verificamos que o desacordo entre o valor do salário e a satisfação das diversas necessidades da vida profissional e pessoal cotidiana é a principal causa dessa insatisfação. Os que se mostram satisfeitos justificam-se na realização de necessidades, na soma de salários e na compatibilidade do valor com a média salarial do mercado de trabalho. Os mo- 
tivos de ingresso em um Programa de BIC refletem, principalmente, o subsídio financeiro como uma forma que teve o egresso de se manter na Universidade, conciliando "trabalho" e estudo, possibilitando a dedicação à vida acadêmica e o seu futuro ingresso no mestrado, primeiro degrau para a carreira acadêmica do ES. Sobre a questão que indaga se as BIC contemplam as necessidades (econômicas, psicossociais, outras) da vida do professor pesquisador (enquanto bolsista e enquanto orientador), os egressos se dividem em suas opiniões e as condicionam: 10 admitiram que "sim", no sentido da BIC como ajuda financeira e 11 avaliam que não ou "não parcial”, devido às ressalvas feitas ao Programa.

$\mathrm{Na}$ avaliação desse egresso professor ES, a questão se as BIC incentivam ou não o aluno bolsista a continuar sua carreira de professor/pesquisador, as justificativas associam, quase sempre, o subsídio financeiro da BIC com outras propriedades do Programa PIBIC. Para o ex-bolsista pobre que sustenta a si próprio, a bolsa foi um subsídio indispensável à sua manutenção na universidade, de forma que a conclusão da graduação significa desamparo, um "momento alto risco" para a continuidade de sua formação acadêmico-científica. Para aqueles que têm a BIC exclusivamente para suas despesas pessoais, já contando com o amparo econômico da família, a bolsa representa um grande incentivo à carreira de professor/pesquisador. Isso quando o egresso não vislumbra a opção de se tornar um pesquisador de uma sólida empresa, caso daqueles que provêm das Ciências Agrárias, onde não registramos nenhum representante nessa subamostra.

Com relação ao objetivo geral, mencionado no início desse trabalho, iremos assinalar algumas constatações e contradições internas identificadas na formação material social que estudamos, em conexão com o seu ritmo histórico. Apesar de numericamente ordenadas, não é intenção estabelecer uma hierarquia entre elas:

1) Uma constatação se dá por marco da Lei 9394/96 (capítulo: “Da Educação Superior"), quando essa abre espaço para o Decreto 2.306/97 (Art. $4^{\circ}$ ) reformar a educação superior, classificando as IES do Sistema Federal de Ensino em: universidades; centros universitários; faculdades integradas; faculdades isoladas; institutos superiores ou escolas superiores. A partir de então, aconteceu a aceleração do processo de privatização da educação superior, no Brasil e na Bahia (FRANCO; FIALHO; PIRES, 2006). A maior parte dos que identificamos na docência da educação superior estão praticando o ensino em faculdades privadas e particulares e, alguns, concomitantemente, como professor substituto, em uma universidade pública. Portanto, sem vínculo que lhes dê condições de ser, realmente, um professor pesquisador universitário profissional, isto 
é, com regime de dedicação exclusiva, realizando pesquisa e recebendo fomento por essa atividade. Registramos um único caso, nessa condição, de um egresso do curso de Química Aplicada;

2) Existe uma contradição entre o aumento gradativo da exigência de "produtividade do pesquisador”, expressas nas últimas resoluções (CNPq. RN-017/2006; RN-025/2005), a ser demonstrada pelo pesquisador para ser um orientador do Programa e as condições de realização do trabalho da pesquisa científica, no tradicional locus de sua produção - a universidade. Segundo ficou demonstrado, em depoimentos dos egressos PIBIC/UNEB, em confronto com a análise bibliográfica e documental, o professor/pesquisador vem sendo compelido a buscar recursos para suas pesquisas em outras fontes fora da Universidade ("pesquisador empreendedor”), ainda que desenvolvida no espaço público. Impulsionado por contradições como essa, o governo criou a Lei das Inovações (BRASIL. Projeto de lei $n^{\circ} 3.476 / 04 ;$ BRASIL. Lei $n^{\circ} 10.973 / 04$ ) e suas atualizações e complementações (tais como a Lei das Fundações de apoio ou amparo às universidades, dentre outras). Em correspondência a esse processo, encontramos a situação de um entrevistado (E7), como pesquisador de um projeto interinstitucional de pesquisa, com fomento de uma agência estadual e em conexão com um programa federal. Outros depoimentos revelam como esse processo contraditório vem se refletindo na pesquisa da IC, conforme expressou esse entrevistado (E6): “A gente pesquisava, analisava, mas não conseguia concluir [...] e tínhamos até receio sobre isto, de como lidar com isto, como falar da empresa que está sendo a parceira, que está lhe cedendo todos os materiais que está sendo possível pesquisar?";

3) Dos objetivos relacionados aos orientadores (CNPq. RN-017/2006): "estimular pesquisadores produtivos a engajarem estudantes de graduação na atividade de iniciação científica e tecnológica [...] [foi acrescentado] integrando jovens em grupos de pesquisa e identificando precocemente vocações, de forma a acelerar o processo de expansão e renovação do quadro de pesquisadores", apreendemos uma correspondência, entre o propósito de identificar precocemente vocações e a real expansão de mestres e doutores, no país. Trata-se de uma aparente harmonia que encontra sustentação ideológica, na concepção idealista do pesquisador. Calcada em valores individualistas e pessoais, desconsiderando o caráter histórico do conhecimento, como pressupõe o materialismo dialético, 
tal concepção pibiquiana, do pesquisador talentoso por vocação, se contradiz à cotidianidade demonstrada pelos depoimentos dos egressos PIBIC/UNEB professor da ES que refletiram suas precárias condições de trabalho. Essa contradição está refletida nas avaliações dos egressos, sobre a importância do Programa na formação do professor pesquisador: "a contribuição financeira não contempla a realidade da vida do aluno/bolsista"; "a bolsa é insipiente para comprar livros, participar de eventos científicos, fazer um curso de línguas". Porém, também encontra correspondências, materializadas nas consciências desses egressos professores, quando alguns afirmam estar satisfeitos com a sua situação salarial e também quando analisam a sua trajetória de bolsista PIBIC/ UNEB, alcançando o momento atual, com ênfase nos esforços próprios;

4) Existe contradição entre o objetivo das RN do PIBIC/CNPq, quando expressa que o Programa se destina a formar quadros (clientela) para a pós-graduação e o fato dessa mesma Agência não oferecer uma quantidade de bolsas suficiente para o egresso prosseguir com o mestrado e o doutorado. O balizamento dessa contradição está nas próprias RN, quando sinalizam para o orientador a tarefa de identificar "talentos precoces”, de forma a escamotear a real intenção do CNPq: de que apenas alguns alunos se tornem pesquisadores. Reflexo dessa situação é fala dos egressos quando se referem ao "status” como uma “distinção” acadêmica e pessoal que o aluno/bolsista adquire em relação aos demais colegas, dentro da universidade.

5) Constatamos que o PIBIC inaugura, no CNPq, o sistema de quotas institucionais, como uma nova modalidade de fomento para formação de recursos humanos para a pesquisa, desde a graduação. Pretendeu, com isso, incentivar pesquisadores produtivos e incrementar e/ou fazer emergir grupos de pesquisa na Instituição. Subtende-se que os bolsistas PIBIC vão interagir com orientadores/pesquisadores e com outros colegas, também bolsistas, de outros níveis de formação, o stricto sensu. Ou seja, está expressa, nas RN, uma intenção de que a pesquisa seja desenvolvida pelo grupo, em suas diversas linhas, onde se dará a formação do bolsista. Essa formação ganha, assim, a aparência de um trabalho de cooperação, em grupo, a ser desenvolvido em uma instituição que ofereça condições para a produção da pesquisa e, mais recentemente, naquelas que possam, rapidamente, desenvolver pesquisa de aplicação comercial. Em contradição a essa idéia de cooperação do trabalho em grupo está a prática do 
"Comitê Externo" que avalia o trabalho do futuro pesquisador, tendo por princípio identificar "talentos precoces" que possam ser produtivos, rapidamente, e com sistema de premiação que auxilie essa identificação, enfim, por critérios de competitividade. Um egresso assim avaliou esse momento:

Acredito que o que atrapalhe um pouco o PIBIC seja essa cobrança por resultados da pesquisa [...] Mas o (a) bolsista tem que apresentar os resultados na jornada, tem que trazer coisas novas [...] Ou seja, dá-se mais valor aos resultados do que ao processo que o (a) bolsista e seu (a) orientado (a) passaram. [...] No final de um ano o bolsista(a) tem que apresentar resultados, fazer resumo. No dia da Jornada tem pouco tempo para apresentar-se e ainda tem que se submeter a perguntas de uma pessoa que não sabe o que você passou o ano todo e que só leu o seu resumo. Quando não o ler durante a sua apresentação. E inspecionar seu banner para ver se o (a) bolsista colocou tudo que é pedido (egresso da subamostra casual).

6) Segundo a RN 015/2004, as bolsas PIBIC continuam destinadas às instituições públicas, comunitárias ou privadas, “com ou sem curso de graduação, que efetivamente desenvolvam pesquisa e tenham instalações próprias para tal fim". Tal afirmação contradiz o que expressa a conceituação do Programa, nessa mesma RN: "alunos de graduação universitária". Concomitantemente, foram retiradas expressões como "novos talentos" ou "vocação científica" que expressavam a concepção idealista da ciência. Compreendemos isso como um avanço para a perspectiva de um constructo social da pesquisa científica e de seu realizador, visto que a mencionada Resolução emerge no marco de legislações como a Lei da Inovação Tecnológica e outras. Ou seja, entendemos que essa contradição revela o resultado de uma luta política, em torno da questão de como transferir ou "inserir" a C\&TI no setor produtivo, de direito público ou privado, e que tais negociações vão sendo assimiladas e corporificadas, nas resoluções do PIBIC/CNPq e refletidas na experiência profissional dos entrevistados.

7) Durante o tempo de duração do fenômeno material social em estudo (1997-2007), observamos que as agências, CAPES e CNPq, vão caminhando juntas na formulação e execução de uma política de formação de pesquisadores, desde a graduação, enquanto reguladoras da produção acadêmico-científica da Universidade. Isso acontece na medida em que os critérios de concessão de bolsas do PIBIC vão sendo atrelados aos 
resultados das avaliações CAPES para os programas de pós-graduação, nas IES de todo o país. Assim, o PIBIC passa, cada vez mais, à margem dos Colegiados de curso, pois é administrado pelas pró-reitorias de pesquisa e pós-graduação das universidades e é avaliado, diretamente, pelo CNPq. O perfil de "experiência" ou produtividade do pesquisador/ orientador vem sendo, progressivamente, também monitorado pelo sistema CAPES, como um critério de concessão das bolsas nas instituições, a partir do nível de classificação obtido pelo curso, junto a essa Agência.

8) Constatamos que o objetivo de "contribuir para, na próxima década, diminuir as disparidades regionais na distribuição da competência científica no território brasileiro", incluído na RN 06/1996, não foi alcançado, pois, conforme demonstramos, a produção acadêmico-científica do país continua concentrada nas regiões sudeste e sul. O PIBIC esperava conseguir esse objetivo através de uma "excepcionalidade" incluída nos "requisitos e compromissos do orientador", qual seja, a de que nas regiões Norte, Nordeste e Centro-Oeste (exceto o Distrito Federal), o orientador, mestre ou doutor, pudesse orientar dois ou três bolsistas, respectivamente. Contraditoriamente, antes de completar uma década, a RN 15/2004 retira o objetivo mencionado e a "excepcionalidade” que estrategicamente poderia possibilitá-lo, deixando à critério da instituição o número de bolsas a ser concedida ao orientador, “em função de sua competência”. Transparece o critério de "pesquisador produtivo e competente" como prevalecente sobre qualquer outro, o qual vem sendo aperfeiçoado, à medida que o empreendedorismo vem se firmando como um valor no perfil desejado para o pesquisador orientador. Analisando o desenvolvimento dos "Critérios" para ser orientador do PIBIC, observamos nas RN que a ênfase dá-se na perspectiva da formação do “pesquisador” para atuar em "qualquer atividade profissional" (em qualquer setor) e não do professor como pesquisador universitário. Para isso, a RN 17/2006 agregou, aos dois objetivos gerais anteriores que vêm sendo mantido, o de "contribuir para a formação científica de recursos humanos que se dedicarão a qualquer atividade profissional" e, ao objetivo específico relacionado aos orientadores, é acrescentada a palavra "profissional".

9) Constatamos também que a responsabilidade das despesas de qualificação docente, para uma pós-graduação, vem sendo assumida como "investimento", pelo próprio egresso/docente ES que, dada a escassez de bolsas, leva adiante a sua formação stricto sensu, enquanto segue trabalhando 
em mais de uma IES e, concomitantemente, tentando a seleção ou já cursando o mestrado ou o doutorado, em uma universidade pública. A essa situação do egresso professor ES se junta a pressão do Programa de Pós para que essa formação se realize no menor tempo possível, uma vez que esse é um dos critérios utilizados pela CAPES, em suas avaliações desses cursos. O resultado é desastroso para a formação do professor pesquisador, sob nosso ponto de vista: o egresso professor ES tem um menor tempo de dedicação aos estudos e uma baixa qualidade de vida, com reflexos em sua saúde, física e mental, o que se reverte na realização de seu trabalho, sob precárias condições. Acreditamos que assim, estamos caminhando para tipos de formação pós-graduada e científica do tipo "bancária”, isto é, sem reflexão, sem meditação sobre o objeto de estudo, sem utilização de uma lógica científica (seja formal ou dialética), sem formação filosófica e sociológica, enfim, uma realização pontual e fragmentada da formação acadêmico-científica. A formação reflexiva e crítica que o Brasil necessita, requer tempo e maturação, que transita na contra mão da tendência do imediatismo que assume a atual conjuntura da pós-graduação:

Então, a gente sente essa pressão e essa pressão se reflete na aula ... saio da aula às vezes achando que poderia ter feito muito melhor e que não fiz porque tô estressada, tô com um nível de estresse muito alto. Isso reflete fisicamente, também, tem aqueles dias em que a gente acha que não vai ser possível seguir a semana, porque o corpo não agüenta mais e, claro, isso vai indo refletir na pesquisa, porque tem dias que a gente não quer nem olhar pras entrevistas, pra alguns dados que precisam ser tratados, pra um livro que precisa ler, porque tá num acúmulo, eu tô num ritmo desenfreado e pra quem tá fazendo mestrado, eu precisaria estar, agora, bem mais tranqüila (Egresso entrevistado - E2).

10) Não está sendo estimulante para o egresso PIBIC galgar a carreira científica até o doutorado. O mercado de trabalho do ensino superior, cada vez mais dominado por IES privadas, não está à procura do doutor, mas do professor "horista". É essa a tendência que se verifica, a partir de dados dos últimos censos da Educação Superior (INEP, 2006), enquanto as IES públicas, estaduais e federais, não oferecem concurso com regularidade e com número de vagas suficientes, indo à busca do professor substituto.

11) Assim, certos objetivos do PIBIC como "formar clientela para a pósgraduação”, soam como formalidades, quando são confrontados com a 
diferença, entre o número e o valor de bolsas do PIBIC e o número e o valor de bolsas oferecidas por essa mesma Agência, nas modalidades de mestrado, doutorado e pós-doutorado. Materializado na fala dos egressos e verificado nos dados do $\mathrm{CNPq}$, esse dado real traz a seguinte indagação: o CNPq está, de fato, interessado em tornar mestres e doutores, os seus 18.782 bolsistas PIBIC existentes, hoje (mar./2008), em todo o Brasil? Ou o CNPq está interessado em identificar, dentre tantos, aqueles que tenham "talentos especiais" para ser um pesquisador, em correspondência com uma concepção idealista do pesquisador, até recentemente compreendida pelo Programa?

12) Para o ex-bolsista PIBIC, superar as contradições da sua formação de aprendiz de pesquisador é uma condição de classe. A "elite pensante" é, também a elite economicamente dominante que, enquanto classe, pensa com uma ética formal e tradicional e não com a ética da práxis humana, que tenha no seu cerne a concepção de novas relações inter-humanas, a partir do concreto, da prática como convivência e produção entre os homens:

Hoje, a maior dificuldade que tenho e que me impede de fazer um mestrado é que tenho que trabalhar 40h para me manter e manter minha família. Acabei de sair do estágio probatório da Prefeitura e agora quem sabe eu consiga fazer mestrado. Tomara que haja novas oportunidades para um mestrado, em algum país da África, pois é onde gostaria de ampliar meus estudos (egressa PIBIC/UNEB, curso de Pedagogia, amostra casual).

\section{Conclusão e proposições}

As experiências profissionais dos egressos, materializada em suas falas e meditadas pela perspectiva teórico-filosófica que adotamos, expressam o refutamento da nossa tese. Ou poderíamos dizer o "quase” refutamento, se aceitarmos a idéia de que o egresso PIBIC/CNPq-UNEB é "quase" um professor/ pesquisador, parafraseando o que vem se chamando de "quase” mercado. Mas, um professor da educação superior, nas condições de trabalho demonstradas na tese, dificilmente poderá desenvolver pesquisa de um bom nível de qualidade. Teremos estatísticas maiores evidenciando o crescimento "acelerado" de mestres e doutores, porém, a ciência nesse país precisa dar o salto qualitativo. Para isso é indispensável que a formação de novas gerações de pesquisadores 
esteja voltada para o esforço intelectual de conversão do modo formal para o modo dialético de pensar, acelerando a transformação necessária na maneira de produzir a ciência.

Os egressos do PIBIC/CNPq-UNEB nos fizeram representantes deles; buscamos, com esforço, refletir a participação de cada um em nosso trabalho, no momento em que eles nos descreveram as histórias de suas vidas. A partir delas podemos dizer que, indiscutivelmente, o ex-bolsista de PIBIC/UNEB não se torna um professor/pesquisador. E, reconhecendo que esse não é um caso isolado, mas inserido em uma totalidade concreta que o condiciona, induzimos que o egresso do PIBIC/CNPq não se torna um professor pesquisador, ao egressar da universidade.

Entretanto, o fôlego do nosso trabalho é a esperança. Com a finalidade de contribuir para tornar realidade a superação das contradições encontradas, entre os propósitos do $\mathrm{PIBIC/CNPq} \mathrm{e} \mathrm{a} \mathrm{prática} \mathrm{profissional} \mathrm{de} \mathrm{seus} \mathrm{egressos,} \mathrm{elabora-}$ mos proposições destinadas ao poder público, federal e estadual, representados, em particular e respectivamente, pelo CNPq e pela UNEB, acatando, assim, as "recomendações" contidas nas avaliações dos egressos.

Indicamos o aumento do número e do valor da bolsa BIC, atualizada sucessivamente, para que o aluno/bolsista possa se manter na Universidade, dedicando-se exclusivamente, aos estudos.

Indicamos a necessidade de estudar a relação orientador/bolsista, partindo do problema de como está se dando a iniciação desse estudante, na produção do conhecimento: como mão-de-obra para auxiliar a construção da carreira do orientador/ pesquisador ou como formação inicial de uma profissão acadêmico-científica?

Indicamos estudos para o aprofundamento do que se sugere, em termos de políticas públicas, com a palavra "profissional" agregada a um dos objetivos do PIBIC, quando se refere, especificamente, ao orientador (Anexo III da RN017/2006). O que vem a ser um "pesquisador profissional"?

Indicamos que a concepção de um Programa de preparação de novas gerações de trabalhadores pesquisadores tenha, por princípio, uma formação geral, filosófica, metodológica, orientada para a transformação qualitativa da produção acadêmico-científica do país, permitindo a passagem da atitude formalista e metafísica de pensar a realidade, predominante na Academia, para a fase em que se evidencia a conveniência de aceitar e desenvolver as concepções dialéticas, aplicadas à ciência e à investigação do mundo.

Indicamos que as políticas de CT\&I sejam pensadas a partir da concepção do pesquisador como um trabalhador, não como um ser idealizado e talentoso, de forma a superar a divisão social do trabalho intelectual e manual. 
Indicamos que se abram e se intensifiquem as linhas de financiamento de pesquisa sobre movimentos sociais, que emergem no país, como forma de motivar a formação de pesquisadores que tomem por objeto de seu estudo, perspectivas reais de transformação do atual modo de produção capitalista. O Brasil precisa formar uma "elite de intelectuais" que seja autoconsciente e crítica, conforme recomendou Gramsci (2004).

Que também se abram, e/ou se intensifiquem, linhas de pesquisa que busquem pensar a educação ensino superior, em conexão com o ensino médio e o ensino fundamental. A formação inicial do professor pesquisador deve ser planejada e realizada na totalidade da formação do ser humano, focando o profissional que trabalha com a educação, em todos esses níveis.

Que a comunidade do ensino superior da Bahia crie meios de denunciar o processo de mercantilização e desnacionalização da Educação Superior, exigindo do poder público medidas para regulamentar o ensino privado e barrar a ingerência do capital estrangeiro no setor.

Recomendamos ao CNPq que, junto às quotas institucionais anuais do PIBIC, seja adicionada certa quantidade de quotas extras destinadas ao propósito da avaliação do Programa, de forma a estimular pesquisadores das universidades a realizarem o acompanhamento da prática profissional dos egressos do Programa, sistematicamente. A falta de uma política de incentivo ao acompanhamento de egressos do PIBIC/CNPq gera desperdícios ao país, pois possibilita o descaminho do ex-bolsista para outras atividades, como forma emergencial de sobrevivência.

Indicamos ao CNPq estudos sobre o custo cotidiano para um bolsista PIBIC, na universidade e que tal estudo tenha uma abordagem teórico-metodológica crítica, social e política, capaz de adotar o conceito de "classe social” compreendendo-a como processo e relação social (WOOD, 2003), tornando-a visível no contexto da luta de classe. Com a convencional abordagem que concebe classe social como "localizador estrutural", isto é, que a toma por critérios de rendimento econômico, oportunidade de mercado ou mesmo ocupação, a essência desse conceito não se revela.

Propomos à UNEB, particularmente, uma recomendação aos orientadores: que convençam seus bolsistas a lerem e discutirem a Resolução Normativa em vigor, pois praticamente todos os entrevistados demonstraram que não conheciam essa legislação.

Para finalizar, desejamos lembrar que, com essa pesquisa, a Universidade do Estado da Bahia se coloca com uma particularidade que a distingue de outras, perante o CNPq: os seus resultados mostram que os egressos do PIBIC/UNEB 
estão alcançando o mestrado, na medida julgada satisfatória por essa Agência (ARAGÒN, 1999). Se a UNEB não fez mais, as causas estão ligadas a problemas gerais que a educação superior vem enfrentado, guardadas as devidas limitações singulares. Quando essa Universidade demonstra para aquela Agência que vem realizando o acompanhamento dos seus egressos PIBIC, ela ganha força para pleitear uma nova quantidade de bolsas desse Programa. O conhecimento gerado por esse estudo conceder à UNEB sustentação técnica necessária a essa solicitação. Por outro lado, também deste modo é demonstrado à Universidade, objetivamente, o retorno do investimento que fez em nossa formação.

\section{Referências}

ALBUQUERQUE, Eduardo. et al. A distribuição espacial da produção científica e tecnológica brasileira: uma descrição de estatísticas de produção local de patentes e artigos científicos. Revista Brasileira de Inovação, Rio de Janeiro, v. 1, n. 2, p. 225-251, jul./dez. 2002.

ALMEIDA, Maria de Lourdes Pinto de. Universidade pública e iniciativa privada: os desafios da globalização. Campinas, SP: Alínea, 2002.

ANTUNES, Ricardo. (Org.). Riqueza e miséria do trabalho no Brasil. São Paulo: Boitempo, 2006.

ARAGÓN, Virgílio. (Coord.) O Programa Institucional de Bolsas de Iniciação Científica (PIBIC) e a sua relação com a formação de cientistas: relatório final. Brasília: UNB/ NESUB, 1999.

BRASIL. Lei $n^{\circ} 5540 / 68$, de 28 de novembro de 1968. Fixa normas de organização e funcionamento do ensino superior e sua articulação com a escola média e dá outras providências. In: SENADO FEDERAL. Secretaria de Informação e documentação. Subsecretaria de Informações. Legislação Republicana Brasileira. Brasília, 2002. 1 CD ROM.

BRASIL. Congresso Nacional. Constituição da República Federativa do Brasil (1988). São Paulo: Saraiva, 2003.

BRASIL. Ministério da Administração e Reforma do Estado. Plano diretor da reforma do aparelho de Estado. Brasília, 1995.

BRASIL. Lei $\mathrm{n}^{\circ}$ 9394, 20 de dezembro de 1996. Estabelece as diretrizes e bases da educação nacional. Diário Oficial [da República Federativa do Brasil], Brasília, DF, 23 dez. 1996. Seção I, p. 27.833-27.841. Disponível em: <http://www.mec.gov.br/legis/default. shtm.>. Acesso em: 10 abr. 2003. BRASIL. Decreto $\mathrm{n}^{\circ} 2.306$, de 19 de agosto de 1997. Regulamenta, para o Sistema Federal de Educação Superior, as disposições contidas no art. 
10 da Medida provisória n 1.477-39, de 08 de agosto de 1997, e dá outras providências. Diário Oficial [da República Federativa do Brasil], Brasília, DF, 19 ago. 1997. Seção I.BRASIL. Lei n ${ }^{\circ}$ 10.973/04, de 2 de dezembro de 2004. Dispõe sobre incentivos à inovação e à pesquisa científica e tecnológica no ambiente produtivo e dá outras providências. Diário Oficial [da República Federativa do Brasil], Brasília, DF, 3 dez. 2004. Seção I. BRASIL. Projeto de lei no 3.476/04. Lei das Inovações. Dispõe sobre incentivos à inovação e à pesquisa científica e tecnológica no ambiente produtivo e dá outras providências. Diário Oficial [da República Federativa do Brasil], Brasília, DF, nov. 2004. Seção I. Disponível em: <http://win. biominas.org.br/biominas2008/images_up/documentos//lei_inovacao.pdf>. Acesso em: 04 mar. 2008.

BÚRIGO, C. C. D. Universidade Pública Federal Brasileira: democraticamente massificada. REXE. Revista de Estudios y Experiencias en Educación de la Universidad Católica de la Santísima Concepción. Concepción, Chile, v. 1, p. 105-123, 2007.

CALAZANS, Julieta. A iniciação científica: um aprendizado do trabalho científico da realidade social. Educação em questão, Natal, v. 1, n. 1, p. 190-196, 1987.

(Org.). Iniciação científica: construindo o pensamento crítico. 2. ed. São Paulo: Cortez, 2002.

CHAUÍ, Marilena. A universidade em ruínas. In: TRINDADE, Hélgio (Org.). Universidade em ruínas: na república dos professores. Petrópolis, RJ: Vozes; Rio Grande do Sul: CIPEDES, 1999. p. 211-222.

CHEPTULIN, Alexandre. A dialética materialista. São Paulo: AlfaOmega,1982.

CNPq (1951). História. Disponível em: <http://www.cnpq.br/sobrecnpq/ historia.htm>. Acesso em: 17 dez. 2005.

CNPq. IC Junior. Disponível em: <http://www.cnpq.br/bolsas_auxilios/ modalidades/ic_junior.htm>. Acesso em: 26 jan. 2006.

CNPq. PIBITI. Disponível em: < http://www.cnpq.br/programasespeciais/ pibiti/index.htm>. Acesso em: 14 fev. 2008

CNPq. Programa Institucional de Bolsas de Iniciação Científica.

Disponível em: <http://www.cnpq.br/index.htm>. Acesso em: 01 fev. 2007.

CNPq. RN-005/1993. Programa Institucional de Bolsas de Iniciação

Científica - PIBIC. Disponível em: <http://memoria.cnpq.br/bolsas_auxilios/ normas/rev/rn0593.pdf>. Acesso em: 04 fev. 2008.

CNPq. RN-006/1996. Programa Institucional de Bolsas de Iniciação

Científica - PIBIC. Disponível em: < http://memoria.cnpq.br/bolsas_auxilios/ normas/rev/rn0696.pdf>. Acesso em: 04 fev. 2008. 


\section{CNPq. RN-015/2004. Programa Institucional de Bolsas de Iniciação}

Científica - PIBIC. Disponível em: <http://memoria.cnpq.br/bolsas_auxilios/ normas/rev/rn1504.pdf>. Acesso em: 04 fev. 2008.

CNPq. RN-025/2005. Programa Institucional de Bolsas de Iniciação

Científica - PIBIC. Disponível em: <http://memoria.cnpq.br/bolsas_auxilios/ normas/rev/rn2505.pdf>. Acesso em: 04 fev. 2008.

\section{CNPq. RN-017/2006. Programa Institucional de Bolsas de Iniciação}

Científica - PIBIC. Disponível em: <http://memoria.cnpq.br/bolsas_auxilios/ normas/rn1706.htm>. Acesso em: 04 fev. 2008.

DIAS SOBRINHO, J. Dilemas da educação superior no mundo

globalizado: sociedade do conhecimento ou economia do conhecimento? São Paulo: Casa do Psicólogo, 2005.

Insular, 2002.

Universidade e avaliação: entre a ética e o mercado. Florianópolis:

EAGLETON, Terry. Marx e a liberdade. São Paulo: UNESP, 1999.

FRANCO, Maria Estela Dal Pai; FIALHO, Nadia; PIRES, Regina. Educação superior brasileira - Bahia - 1991-2004. Brasília/DF: INEP, 2006.

GRAMSCI, Antônio. Cadernos do cárcere. Trad. Carlos Nelson Coutinho; co-edição, Luiz Sérgio Henriques e Marco Aurélio Nogueira. 3. ed. Rio de Janeiro: Civilização Brasileira, 2004. v. 1.

INEP. Sinopse. Censo Superior 2006. Disponível em: <http://www.inep.gov. br/superior/censosuperior/sinopse>. Acesso em: 02 mar. 2008.

KOSIK, Karel. Dialética do concreto. 7. ed. Rio de Janeiro: Paz e Terra, 2002. LEITE, Denise. Reformas universitárias: avaliação institucional participativa. Petrópolis, RJ: Vozes, 2005.

Aprendizagem e consciência social na universidade. 1990. $192 \mathrm{f}$.

Tese (Doutorado em Educação) - Programa de Pós-Graduação em Educação, Faculdade de Educação, Universidade Federal do Rio Grande do Sul, Porto Alegre, 1990.

MARCUSCHI, Luíz. Avaliação do Programa Institucional de Bolsas de Iniciação Científica (PIBIC) do CNPq e propostas de ação: relatório versão final. Recife: URPE, 1996.

MARX, Karl. Contribuição à crítica da economia política. 2 ed. São Paulo: Martins Fontes, 1983.

MARX, Karl.. O capital. Rio de Janeiro: Civilização brasileira, 2002. Livro I. MARX, Karl; ENGELS, Frederich. A ideologia alemã. São Paulo: Moraes, 1984.

MÉSZÁROS, István. Educação para além do capital. São Paulo: Boitempo, 2005. 
MÉSZÁROS, István. O poder da ideologia. São Paulo: Boitempo, 2004. OLIVEIRA, Francisco de. Crítica à razão dualista: o ornitorrinco. São Paulo: Boitempo, 2003.

PINTO, Álvaro Vieira. Ciência e existência: problemas filosóficos da pesquisa científica. 2 ed. Rio de Janeiro: Paz e Terra, 1979.

PIRES, Regina. A formação inicial do professor pesquisador universitário no Programa Institucional de Bolsas de Iniciação Científica - PIBIC/CNPq e a prática profissional de seus egressos: um estudo de caso na Universidade do Estado da Bahia. 2008. 356f. Tese (Doutorado em Educação) - Programa de Pós-Graduação em Educação, Faculdade de Educação, Universidade Federal do Rio Grande do Sul, Porto Alegre, 2008.

. Iniciação científica e avaliação na educação superior brasileira. REXE. Revista de Estudios y Experiencias en Educación de la Universidad Católica de la Santísima Concepción. Concepción, Chile, v. 1, p. 125-135, 2007.

A contribuição da iniciação científica na formação do aluno de graduação numa universidade estadual. 2002. 203f. Dissertação (Mestrado em Educação) - Programa de Pós-Graduação em Educação, Faculdade de Educação, Universidade Federal da Bahia, Salvador, 2002.

SANTOS, Boaventura de Sousa. A universidade no século XXI: para uma reforma democrática e emancipatória da universidade. São Paulo: Cortez, 2004. (Coleção questões de nossa época; v. 120).

. Pela mão de Alice. O social e o político na pós-modernidade. 9. ed.

São Paulo: Cortez, 2003.

SILVA JR., João dos Reis. Os limites políticos da democracia na educação superior brasileira delineados por intelectuais da academia. Avaliação, Campinas; Sorocaba, SP, v. 12, n. 3, p. 461-482, set. 2007.

TRIVIÑOS, Augusto et al. A agonia do(a) educador(a) sul-rio-grandense: histórias de vida. Porto Alegre: Ed. UFRGS, 2006.

TRIVIÑOS, Augusto. Método Marxiano (explicação): breve apresentação do método dialético-materialista. Porto Alegre: FACED/UFRGS, 2006a. 17f. (Texto digitado).

. O método dialético na pesquisa nas ciências sociais (documento preliminar de trabalho). Porto Alegre, [s. n.], 2005. 155 f. (Texto digitado).

. Introdução à pesquisa em ciências sociais: a pesquisa qualitativa em educação. São Paulo: Atlas, 1987.

WOOD, Ellen. Democracia contra capitalismo: a renovação do materialismo histórico. Trad. Paulo Cezar Castanheira. São Paulo: Boitempo, 2003. 